\title{
МОДЕРНИЗАЦИОННЫЕ ПРОЦЕССЫ В ЭКОНОМИКЕ РЕГИОНА КАК ПРОБЛЕМА КОНСЕНСУСА ЭЛИТ
}

\author{
(c) 2021 Полторыхина Светлана Валерьевна \\ кандидат экономических наук, доцент, заведующий кафедрой «Финансы и кредит» \\ Казанский Инновационный университет имени В.Г. Тимирясова (ИЭУП), Россия, Казань \\ E-mail: poltoryhina.s.v@mail.ru
}

В статье отражена роль процессов модернизации экономики региона в контексте достижения консенсуса среди господствующих элит. Установлена противоречивость понятия модернизации, сформулированы ее признаки. Дана характеристика целостности процессов формирования и смены технологических укладов, определено соотношение модернизационной динамики со сменой технологических укладов в экономике.

Ключевые слова: модернизация, модернизационная динамика, технологический уклад, государственная инновационная политика, рационализация, социокультурная динамика, инновационная деятельность, экономический рост, экономическое развитие, витрувианский человек.

На уровне официальной государственной риторики признают, что приоритетная задача повышения качества жизни населения России может быть решена только на основе модернизации экономики страны, выражающейся в повышении эффективности использования всех видов ресурсов на основе массового внедрения в практическую деятельность достижений науки и техники, перехода к инновационной экономике. При этом мировой и отечественный опыт показывает, что модернизация не сводима к механистичному трансферту научных достижений в производственную сферу. Как правило, модернизация связана с изменением функционирования социально-экономической системы в целом, формированием новых институтов, формулировкой новых целевых ориентиров и стратегий их достижения.

Достижение целей построения инновационной экономики невозможно без наличия соответствующих индикаторов, позволяющих измерить интенсивность протекания экономических процессов. При существовании большого количества методик оценки инновационной динамики и инновационного потенциала экономических систем различного уровня, как опирающихся на статистические данные, так и на сочетание статистических и экспертных методов, большинство из них ориентировано на сравнительно небольшой, актуальный для данного момента временной горизонт 3-5 лет. При этом трансформационная динамика, связанная с модернизацией и сменой технологических укладов, как правило, связана с более длительными промежутками времени, сопоставимыми с десятилетиями.

При разработке государственной инновационной политики и реализации государственных целевых программ, как правило, оперируют не абстрактным технологическим укладом, который выступает как атрибут модернизационной динамики, а показателями развития конкретных подотраслей экономики, которые ассоциированы с развитием передового уклада. Во многих случаях эти взаимосвязи неочевидны и неоднозначны. В связи с этим представляет интерес рассмотрение взаимосвязи долгосрочной инновационной динамики и уровня цифровизации, характерного для данных экономических систем. Как правило, переход к новому технологическому укладу связан не только с появлением новых производств, но и с проникновением технологий, характерных для него, в производства, аттрибутируемые со старыми технологическими укладами, что способно существенно повысить их эффективность.

Аналитики указывают, что собственно модернизация (ее признаки и результаты) не может быть рассмотрена вне определённого исторического контекста [4]. «Вырванная» из исторического контекста технологическая составляющая не способна объяснить логику развития экономики, а это в свою очередь может привести к искажению имеющихся данных и подмене существующей действительности.

Опираясь на изученные источники, мы мо- 
жем констатировать, что в основе смены технологических укладов лежит модернизация в экономике или в обществе в целом. Понятие «модернизация» в наиболее общем виде рассматривается как комплекс существенных позитивных перемен в экономике и обществе. Более точные и конкретные определения достаточно противоречивы. Рассмотрим некоторые из них.

Леви М. рассматривает модернизацию в большей степени не как событие, а как некий градиент (уровень) развития, характеризующийся способностью использовать неодушевленные источники энергии и механизмы для повышения эффективности деятельности членов сообщества, выражающейся в возможности достижения результата с меньшими усилиями [10]. Лернер Д. определяет модернизацию, прежде всего, как ментальный сдвиг, состояние рассудка, характеризующееся верой в прогресс и изменением стиля жизни, атрибутами которого являются повышение мобильности населения, распространение грамотности и развитие средств массовой информации [9]. Блэк С. определяет модернизацию как исторический процесс, в ходе которого резко повысилась скорость адаптации институтов к изменившимся внешним и/или внутренним условиям их существования, что сопровождается расширением знаний (научной революцией) и возможностью контроля над ситуацией (блокирования исторических вызовов) [7]. Ваго С. сужает историческую арену модернизации до перехода аграрных обществ в индустриальные, соответственно, трансформация технологических и социальных механизмов рассматривается с позиций степени адекватности задачам происходящего перехода [13]. Макридис Р. и Браун Б. в качестве определяющего фактора модернизации рассматривают культурный феномен, связанный с верой в возможности науки и априорной ценностью научного знания [11]. Пай Л. солидарен с Макридисом Р. и Брауном Б. в отношении культурной первоосновы модернизации и ценностного характера научного знания, однако дополняет данную культуру такими характеристиками, как секуляризация (десакрализация) и рационализация общественной жизни, приоритетность национального государства в политической жизни и стремление к установлению справедливых отношений в обществе. Немаловажным является и тот факт, что данная культура имеет свойство распространяться, становясь всеобщей (мировой) [12]. Эйзенштадт Ш. определяет модернизацию как цивилизацию нового типа, которая, транслируясь (распространяясь), устанавливает единые (мировые) институциональные и символические (ценностные) рамки [8]. Белковский С. и Ремизов М. рассматривают модернизацию как процесс становления в конкретном государстве общества модерна, а специфика данного процесса обусловливается конкретной исторической ситуацией [2]. Азрилян А.Н., не претендуя на глобальность, характеризует модернизацию как процесс внедрения изменений соответствующим современным вызовам [1]. Кураков В.Л. солидарен с Азриляном А.Н., уточняя, что процесс модернизации сопровождается институциональными изменениями, в том числе нормативно-правовой базы в технологической сфере [3]. Цапф В. рассматривает понятие модернизации сразу в трех аспектах, которые обобщают ранее рассмотренные формулировки: историческом (длящийся процесс индустриализации), целевом (изменения с целью «догнать», то есть обеспечить уровень благосостояния как в «развитых» сообществах), адаптивном (как реакция общества на вызовы и преобразования) [6].

Обобщая рассмотренные выше определения, можно сформулировать следующие признаки (характерные черты) модернизации: модернизация исторична и нарративна, она вписана в определенный исторический контекст и не может быть понята и реализована вне его, модернизация может быть рассмотрена как результат и процесс социокультурной динамики; модернизация локальна и экспансивна, то есть возникает на ограниченной территории и имеет ярко выраженную тенденцию к распространению; модернизация институциональна и ментальна, что выражается в трансформации институтов и изменении методов принятия решения (способов мышления) в процессе модернизации; модернизация прогрессистски таргетирована, то есть имеет своей целью повышение качества жизни членов сообщества и повышение эффективности их деятельности.

Модернизация не равнозначна смене технологических укладов, однако четко ассоциирована с этим процессом и инновационной деятельностью в целом [5]. Иными словами, учитывая все вышеизложенное, мы можем констатировать, что модернизация - это смена ценностей общества и отдельных индивидуумов, менталь- 
ный сдвиг, способствующий прогрессу. Модернизация - это движущая сила, обеспечивающая экономический рост и развитие, смену технологического уклада.

Целостность процессов формирования и смены технологических укладов может быть схематически представлена в виде условного «витрувианского человека» (рисунок 1).

При этом верхний пояс обобщает «активные» составляющие инновационного цикла: инновации - некоммерциализированные изобретения и открытия; инвестиции в виде различных вложений, предусматривающих получение отсроченного позитивного эффекта; «ресурсы» в виде факторов и средств производства. Нижний пояс обобщает элементы, связанные с обусловленностью текущей деятельности логикой предыдущего развития. Это нарративная составляющая развития представлена сложившейся структурой материальных активов в виде производственных мощностей и инфраструктуры, нематериальных активов в виде явного и неявного знания, становящегося основой для научных открытий и инноваций, сложившейся системы формальных и неформальных институтов.

На рисунке 2 представлено соотношение модернизационной динамики в экономических системах и процесса смены технологических укладов.
Системные показатели связаны с уровнем благосостояния общества опосредованно и поэтому в контексте модернизации, обычно, речь идет о таких целевых показателях как среднедушевые доходы, валовой продукт и др. Применительно к экономическим системам различного уровня целевые показатели могут быть представлены различными статистическими данными. Единым для них является представление со стороны лиц, принимающих решения (правящих элит) о позитивной динамике данных показателей как цели и признака проводимой модернизации.

В рамках модернизационной динамики применительно к технологическому укладу в качестве цели максимум ставится задача смены на новый более прогрессивный технологический уклад, способный изменить характеристики экономической системы или, как минимум, в рамках догоняющей модернизации, увеличении доли прогрессивных укладов в объемах производимых благ. При этом следует учитывать, что если некие причины позволяют поддерживать достаточно высокие характеристики экономической системы, то есть активная составляющая недостаточно мотивирована или мотивация блокируется институтами среды, то смены технологических укладов происходить не будет, а элиты ограничатся псевдо-модерни-

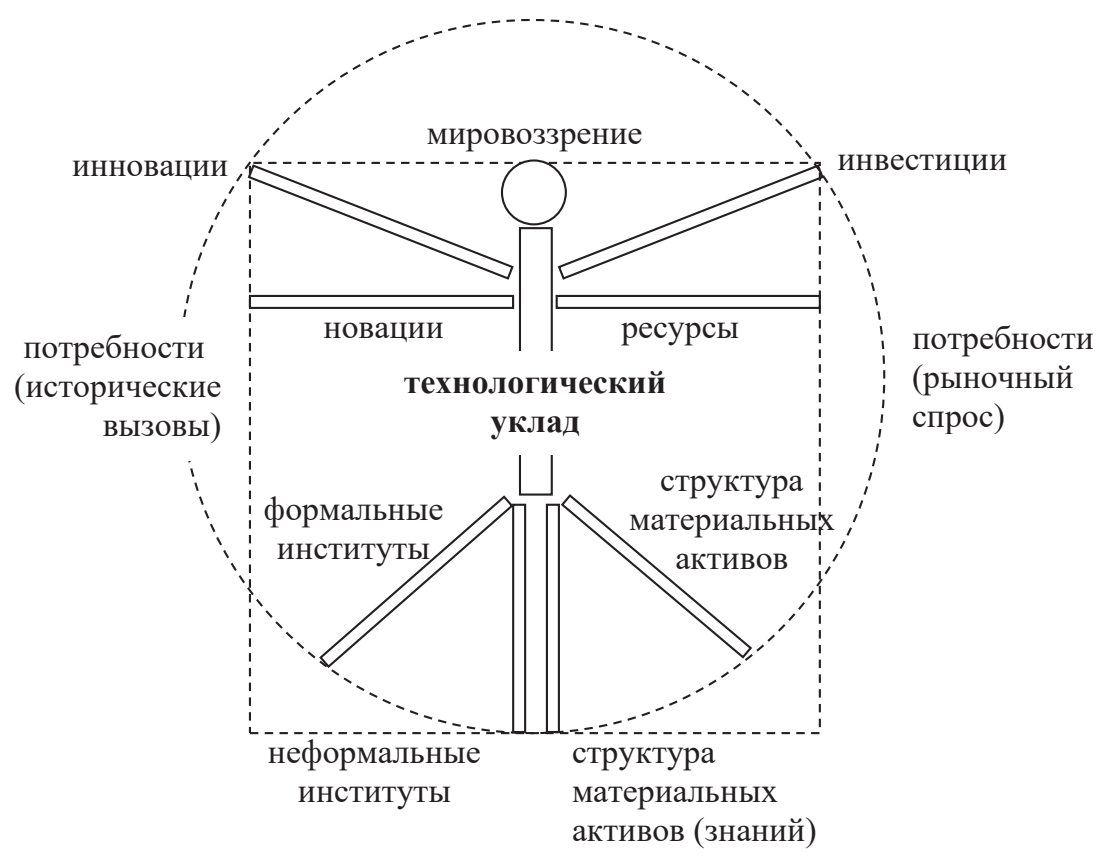

Puc. 1. Технологический уклад как атрибут модернизационной динамики 


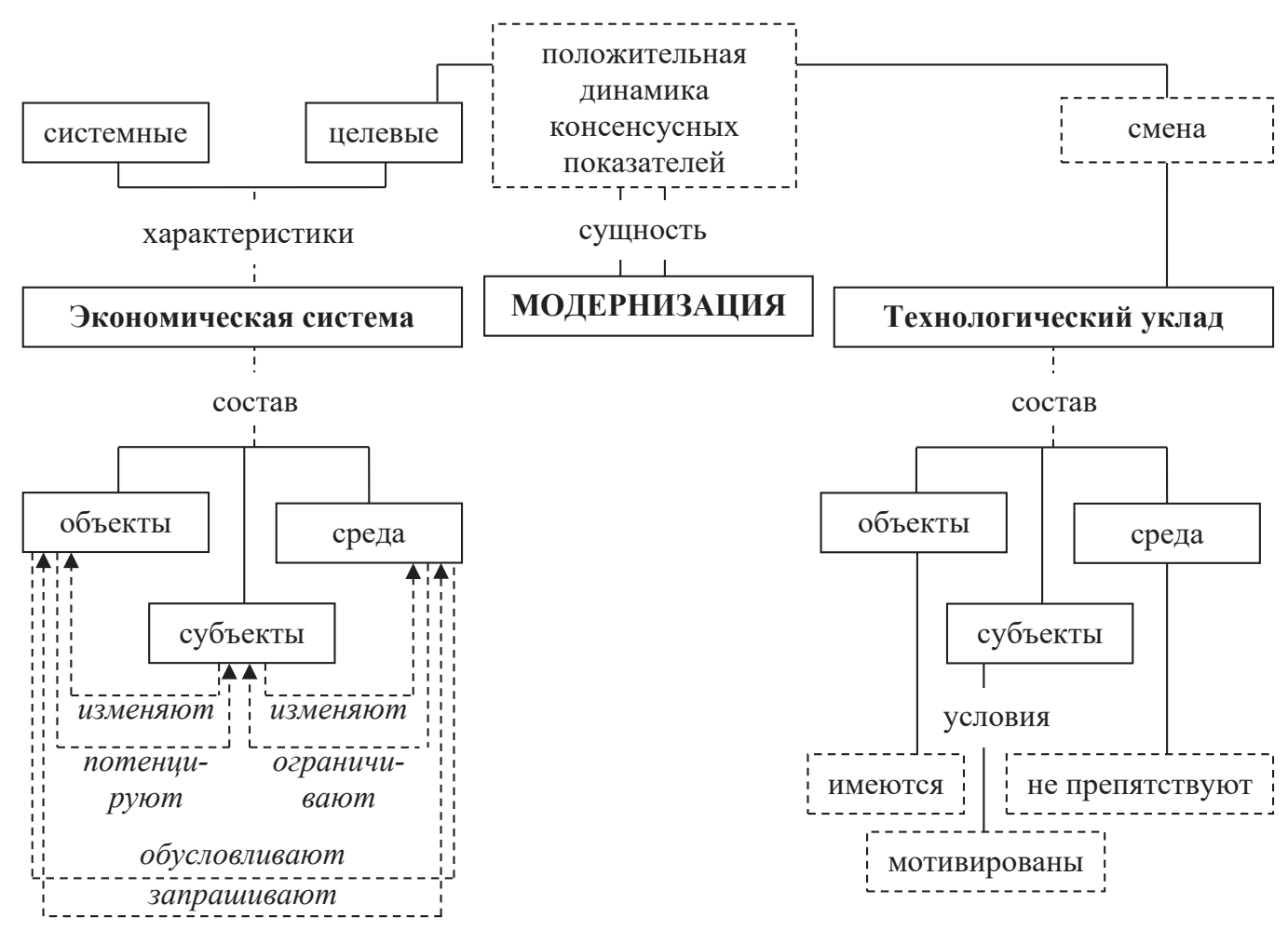

Puc. 2. Соотношение модернизационной динамики в экономических системах и процесса смены технологических укладов

зацией, даже в ущерб долгосрочным перспективам развития.

Таким образом, можно говорить о представленности элементов технологических укладов в экономических системах различного типа и связанности процесса смены технологических укладов с их жизнеспособностью в явном виде, как целевых показателей, декларируемых правящими элитами (акторами), так и системных, проявленность которых в текущей экономической деятельности фиксируется, чаще всего, как свершившийся факт. Задача органов управления экономической системой (правящие элиты на уровне стран или советы директоров для корпоративного уровня) состоит в создании условий, которые способствовали бы возможности проявлений субъектной активности желательного типа.

\section{Библиографический список}

1. Азрилян А.Н., Азрилян О.М., Калашникова Е.В. Большой экономический словарь: 24,8 тыс. терминов. - М.: Институт новой экономики, 2002. - С. 1280 с.

2. Белковский C., Ремизов М. Специальная теория модернизации // Газета. ru. - 2009. URL: http://www.gazeta.ru /comments/2009/10/12_a_3272036. shtml

3. Кураков В.Л., Кураков В.Л., Кураков А.Л. Экономика и право: словарь-справочник: монография. - М.: Вуз и шк., 2004. - 1071 с.

4. Модернизация в предлагаемых обстоятельствах // Эксперт № 1 (687). - 2010. - С. 6-9.

5. Третьяк В.П., Сагина О.А. Модернизационное или инновационное развитие: параметры и стадии // Россия: тенденции и перспективы развития. Ежегодник. Вып. 13. - М., 2018. - Ч. 1. - 1114 с.

6. Цапф В. Теория модернизации и различие путей общественного развития // Социс. - М., 1998. - № 8 . - С. 14.

7. Black C. The Dynamics of Modernization. A Study in Comparative History. - N. Y.: Harper Colophon Books, 1975. - P. 186-187.

8. Eisenstadt S. N. Modernization: Protest and Change. - Englewood Cliffs: Prentice-Hall, 1966. - 166 p.

9. Lerner D. The Passing of Traditional Society: Modernizing the Middle East. -New York; London, 1965. - P. VIII. 
10. Levy M.J. Social Patterns (Structures) and Problems of Modernization // Readings on Social Change. - Englewood Cliffs (NJ): Prentice-Hall, 1967. - P. 196-201.

11. Macridis R. C., Brown B.E. Comparative Politics: Notes and Readings. - Homewood (IL): Dorsey, 1972. - P. 428.

12. Pye L. W. Aspects of Political Development. - Boston, 1965. - P. 8.

13. Vago S. Social Change... // Social Change and Modernization: Lessons from Eastern Europe. - Berlin; New York: De Gruyter, 1995. 